\title{
Cytotoxic Activities of Methanol Extract and Compounds of Porodaedalea pini Against Colorectal Cancer
}

\author{
Ebru Deveci ${ }^{\circledR}$ 1, $^{*}$ Gulsen Tel-Cayan ${ }^{\circledR 2}$, Serdar Karakurt ${ }^{\circledR 3}$, Mehmet Emin Duru ${ }^{(4}$
}

\author{
${ }^{1}$ Department of Chemistry and Chemical Processing Technologies, Technical Sciences Vocational School, Konya \\ Technical University, Konya, Turkey \\ ${ }^{2}$ Department of Chemistry and Chemical Processing Technologies, Muğla Vocational School, Muğla Sitk1 \\ Koçman University, Muğla, Turkey \\ ${ }^{3}$ Department of Biochemistry, Faculty of Science, Selcuk University, Konya, Turkey \\ ${ }^{4}$ Department of Chemistry, Faculty of Sciences, Muğla Sıtkı Koçman University, Muğla, Turkey
}

\begin{abstract}
Porodaedalea pini is a medicinally important mushroom with antioxidant, cytotoxic, immunostimulating, antitumor, antiviral and immunomodulating activities. Therefore, in this study, $P$. pini methanol extract and isolated compounds from the methanol extract were tested for cytotoxic activities against DLD-1 (colorectal cancer) and CCD-18Co (human colon fibroblast cell line) by using Alamar Blue assay. Cytotoxic activity on DLD-1 was decreased in the order of $P$. pini methanol extract> 4-(3,4dihydroxyphenyl)but-3-en-2-one (3)> pinoresinol (2)> ergosta-7,24(28)-dien$3 \beta$-ol (1). $P$. pini methanol extract was determined to have the best cytotoxic activity with the lowest $\mathrm{IC}_{50}$ value on DLD-1 $\left(\mathrm{IC}_{50}: 25.33 \pm 0.29 \mu \mathrm{g} / \mathrm{mL}\right)$ and the highest $\mathrm{IC}_{50}$ value on CCD-18Co $(434.30 \pm 1.45 \mu \mathrm{g} / \mathrm{mL})$. Within the scope of the findings, it is thought that $P$. pini mushroom can be used as a new and natural agent in the treatment of colorectal cancer.
\end{abstract}

\section{ARTICLE HISTORY}

Received: September 11, 2020

Revised: October 11, 2020

Accepted: February 18, 2021

\section{KEYWORDS}

Porodaedalea pini,

Colorectal cancer,

Cytotoxic activity,

Extract,

Isolation

\section{INTRODUCTION}

Cancer ranks second in deadly diseases after cardiovascular diseases worldwide. Approximately $10 \%$ of diagnosed cancers or cancer-related deaths each year consist of colorectal cancer (Dekker et al., 2019). Colorectal cancer is the second most common type of cancer diagnosed in women, while it is third cancer in men. The incidence and mortality in women are about $25 \%$ lower than in men. The worldwide incidence of colorectal cancer is estimated to increase to 2.5 million new cases by 2035 (Arnold et al., 2017; Dekker et al., 2019). Among the causes of colorectal cancer, various risk factors including diets are rich in animal fat, in vegetables and fruits, smoking, diabetes and obesity have been identified (Kelly et al., 2012; Perdue et al., 2014). Also, studies have reported that high consumption of red meat increases the risk of colorectal cancer, while adequate physical activity, especially outdoor activities, and the level of vitamin $\mathrm{D}$ in the bloodstream reduces the risk of colorectal cancer (Oba et al., 2006; Takachi et al., 2011; Surya et al., 2016). Worldwide, nutrition and diet are the most remarkable factors causing colorectal cancer. The literature studies revealed that many

CONTACT: Ebru Deveci $\varangle$ edeveci@ktun.edu.tr $\equiv$ Department of Chemistry and Chemical Processing Technologies, Technical Sciences Vocational School, Konya Technical University, Konya, Turkey 
natural diet products can be beneficial in the prevention of cancer (Tao et al., 2018). Also, plants, fruits, vegetables, herbal teas, and mushrooms have been reported to have cytotoxic effects on colorectal cancer cells and due to the presence of dietary fibers and phytochemical compounds (Turati et al., 2015; Seidel et al., 2017).

In Chinese medicine, Phellinus genus has been reported to be used in the treatment of many diseases such as arthritis of the knee, stomachaches, tumors, inflammation, lymphatic and gastroenteric disorders and to promote longevity in Chinese medicine (Ganeshpurkar et al., 2010; Seephonkai et al., 2011). Bioactive compounds such as sesquiterpenes, triterpenes, steroids, pigments, and polysaccharides, responsible for estrogenic, antiviral, antioxidant, antitumor and anti-estrogenic activity have been purified from Phellinus species (Wu et al., 2010; Song et al., 2014; Wang et al., 2014; Pei et al., 2015). Porodaedalea pini, a member of Phellinus genus and Hymenochaetaceae family, is usually grown under the pine trees. It is known to lower blood sugar, increase immunity, and have anti-cancer properties (Ayer et al., 1996). Antioxidant, antifungal, anticholinesterase, anti-tyrosinase, cytotoxic activities, and inhibition effects on NO production in murine macrophages-RAW 264.7 cells by the compounds isolated from $P$. pini have been revealed by previous studies (Ayer et al., 1996; Wangun \& Hertweck, 2007; Jang \&Yang, 2011; Deveci et al., 2019 ${ }^{\mathrm{a}}$ ). In recent years, the discovery of bioactive compounds from natural sources, and obtaining compounds and possible drug candidates with therapeutic properties have attracted more attention. In this context, mushrooms are considered as sources of natural bioactive compounds and are defined as promising therapeutic agents. The study was aimed to evaluate cytotoxic activities against DLD-1 (colorectal cancer) and CCD-18Co (human colon fibroblast cell line) of both P. pini methanol extract and ergosta-7,24(28)-dien-3 $\beta$-ol, pinoresinol, and 4-(3,4dihydroxyphenyl)but-3-en-2-one compounds isolated from the methanol extract in our previous study (Deveci et al., 2019 ${ }^{\mathrm{a}}$ ).

\section{MATERIAL and METHODS}

\subsection{Mushroom Material}

Porodaedalea pini (Brot.) Murrill. was collected from the villages of Mentese district of Mugla in November-December 2014 and January 2015 from the area of Muğla, Turkey. The voucher specimen has been stored at the Research and Application Center for Mushrooms, Mugla Sitki Kocman University (Fungarium No AT-2446).

\subsection{Spectral Measurements and Chemicals Used}

For purification of the compounds, silica gel (Kieselgel 60, 70-230 mesh, Merck) was used for column chromatography; RP-18 $\mathrm{F}_{254} \mathrm{~S}$ and silica gel $60 \mathrm{~F}_{254}$ plates for thin-layer chromatography (TLC). Separation and isolation of the compounds were performed by using $\mathrm{C}_{18}$ and GS-320 column-linked recycling HPLC (Japan Analytical Industry Co. Ltd.). UV-254$\mathrm{nm}$ light was used for detection of TLC spots and $\mathrm{CeSO}_{4}$ solution for visualization. Chemical structures of the isolated compounds were elucidated by using FT-IR, 1D-NMR, 2D-NMR spectroscopy techniques. Thermo Scientific one Nicolet IS10 FT-IR spectrometer was used to record the IR spectrum. The NMR spectrum was on Agilent-600-MHz instruments coupled with cooled cryoprobes probe for ${ }^{1} \mathrm{H}-$ and ${ }^{13} \mathrm{C}-\mathrm{NMR}$ including HSQC, HMBC, and COSY. A 96-well microplate reader (MultiskanGo, Thermo Scientific Co., MA, USA) was used to analyze cytotoxic activity studies. Cytotoxic activity results were measured and calculated by using GraphPad Prism (GraphPad Software v5.0, USA).

\subsection{Extraction and Isolation}

For extraction of the aerial parts of $P$. pini (1900 g), powdered mushroom samples were macerated separately and respectively in solvents with increasing polarity: $n$-hexane, 
chloroform, acetone, and methanol for $24 \mathrm{~h}$; and four times at room temperature. Solvents were vaporized by using a rotary evaporator. The methanol extract obtained was $49.70 \mathrm{~g}$. The methanol extract was stored at $+4{ }^{\circ} \mathrm{C}$ for further analysis. As a result of the chromatographic isolation of $P$. pini methanol extract, ergosta-7,24(28)-dien-3 $\beta$-ol, pinoresinol, and 4-(3,4dihydroxyphenyl)but-3-en-2-one were obtained. Details about the isolation and characterization of the compounds can be seen in our previously published research (Deveci et al., 2019 $)$.

\subsection{Cell Viability}

CCD-18Co (human colon fibroblast cell line) and DLD-1 (colorectal cancer) were cultivated in EMEM and RPMI-1640 growth mediums (ATCC, Virginia, USA), respectively and incubated with $10 \%$ fetal bovine serum (FBS), $1 \%$ penicillin/streptomycin, $2 \mathrm{mM} \mathrm{L-}$ glutamine (Sigma, St. Louis, Missouri, USA) in 5\% $\mathrm{CO}_{2}$ at $37{ }^{\circ} \mathrm{C}$ and $90-95 \%$ humidity.

\subsection{Cell Viability Assay}

$1 \times 10^{4}$ cells were put into 96-well plate with a growth medium and incubated in $5 \% \mathrm{CO}_{2}$ at $37^{\circ} \mathrm{C}$ for $24 \mathrm{~h}$ until they attached to the bottom. Different concentrations (between $1 \mu \mathrm{g} / \mathrm{mL}$ and $1000 \mu \mathrm{g} / \mathrm{mL}$ ) of the methanol extract and isolated compounds of $P$. pini were added to each well. Viability and proliferation of the cells were tested according to the previously described Alamar Blue assay (Karakurt \& Adali, 2016). The results were measured at $570 \mathrm{~nm}$ and 610 $\mathrm{nm}$ by using a 96-well microplate reader. Doxorubicin was used as a positive control. The sigmoidal plot of the inhibition rate $(\%)$ versus the log concentration was used to calculate the $\mathrm{IC}_{50}$ values of $P$. pini methanol extract and the isolated compounds.

\subsection{Statistical Analysis}

All data on cytotoxic activity tests were the average of three parallel sample measurements. Data were recorded as mean \pm S.E.M. Significant differences between means were determined by $t$-test, $p<0.05$ were regarded as significant.

\section{RESULTS and DISCUSSION}

Ergosta-7,24(28)-dien-3 $\beta$-ol (1), pinoresinol (2), and 4-(3,4-dihydroxyphenyl)but-3-en2-one (3) were obtained as a result of the isolation of $P$. pini methanol extract. Spectroscopic data of the isolated compounds can be seen in our published previous research (Deveci et al., $2019^{a}$ ). Figure 1 shows the chemical structures of the compounds isolated from $P$. pini methanol extract.

Figure 1. Chemical structures of the compounds isolated from P. pini methanol extract.

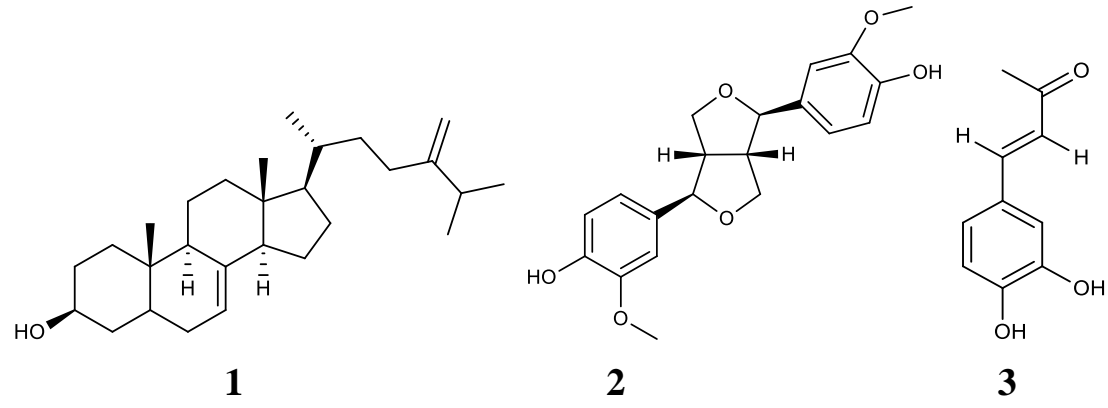

Cytotoxic activities against DLD-1 (colorectal cancer) and CCD-18Co (human colon fibroblast cell line) of $P$. pini methanol extract and ergosta-7,24(28)-dien-3 $\beta$-ol (1), pinoresinol (2) and 4-(3,4-dihydroxyphenyl)but-3-en-2-one (3) compounds isolated from the methanol extract were tested by Alamar Blue assay. DLD-1 and CCD-18Co cells were treated with different concentrations of the methanol extract and isolated compounds. Figure 2 represents 
the cytotoxic effects of $P$. pini methanol extract and isolated compounds on DLD-1 and CCD18 Co.

Figure 2. Cytotoxic effects of $P$. pini methanol extract and isolated compounds on DLD-1 and CCD$18 \mathrm{Co}(\mathbf{a}) \mathrm{IC}_{50}$ values on DLD-1 (b) $\mathrm{IC}_{50}$ values on CCD-18Co (c) Heat Map analyses of dose-dependent inhibition against DLD-1 cells. Cell viability decreased from red to pink color (d) Heat Map analyses of dose-dependent inhibition against CCD-18Co. Cell viability decreased from green to pink color.

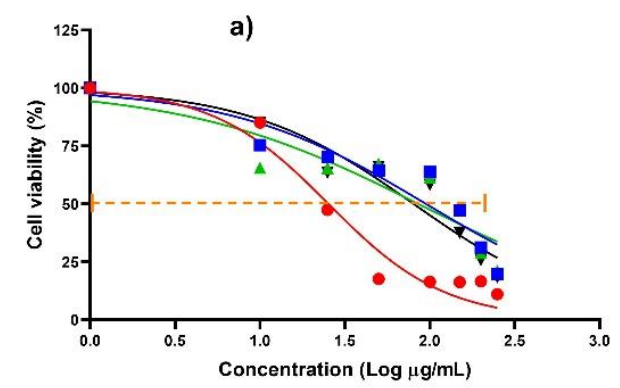

c)

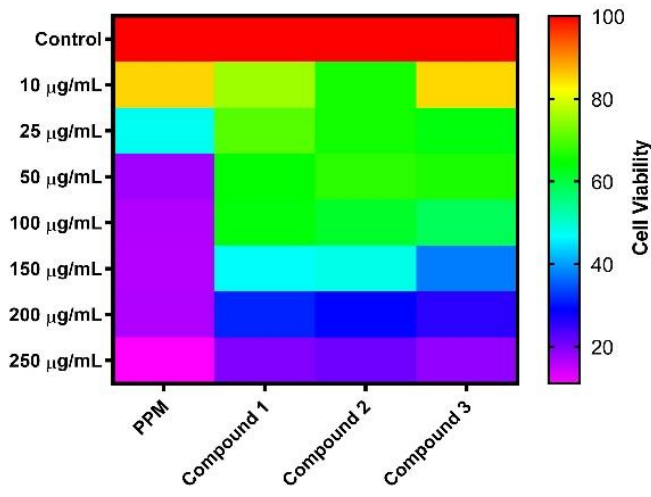

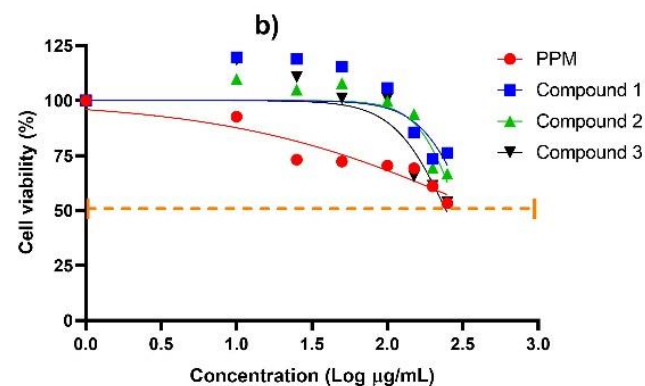

d)

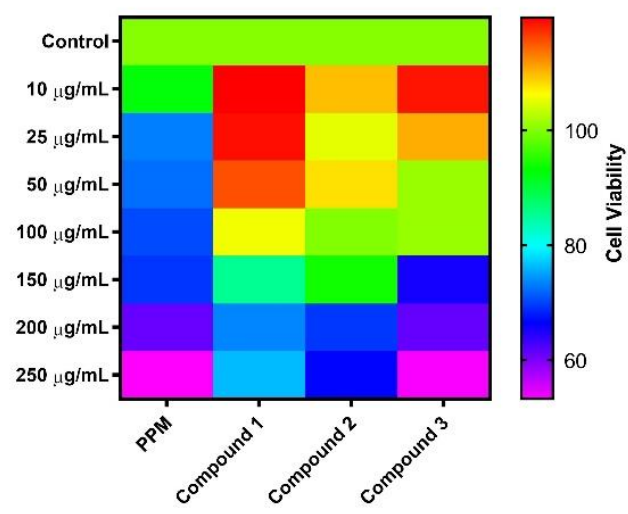

Table 1. Calculated $\mathrm{IC}_{50}$ values of the methanol extract and isolated compounds of P. pini ${ }^{\mathrm{a}}$

\begin{tabular}{ccc}
\hline & DLD-1 & CCD-18Co \\
$\mathrm{IC}_{50}(\mu \mathrm{g} / \mathrm{mL})$ & $\mathrm{IC}_{50}(\mu \mathrm{g} / \mathrm{mL})$ \\
\hline Methanol extract (PPM) & $25.33 \pm 0.29$ & $434.30 \pm 1.45$ \\
Ergosta-7,24(28)-dien-3 $\beta$-ol (1) & $95.05 \pm 1.25$ & $347.20 \pm 0.78$ \\
Pinoresinol (2) & $85.69 \pm 0.87$ & $293.90 \pm 0.46$ \\
4-(3,4-dihydroxyphenyl)but-3-en-2-one (3) & $80.32 \pm 0.98$ & $245.20 \pm 0.34$ \\
Doxorubicin $^{\mathrm{b}}$ & $6.10 \pm 0.55$ & $\mathrm{NT}^{\mathrm{c}}$
\end{tabular}

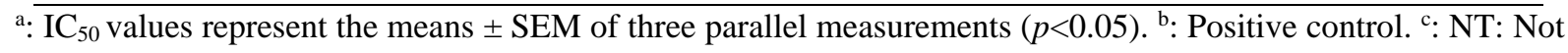
tested.

Table 1 shows the calculated $\mathrm{IC}_{50}$ values of $P$. pini methanol extract and isolated compounds. As seen in Figure 2, P. pini methanol extract and isolated compounds inhibited the viability of DLD-1 and CCD-18Co in a dose-dependent manner. Cytotoxic activity on DLD-1 was decreased in the order of $P$. pini methanol extract $\left(\mathrm{IC}_{50}: 25.33 \pm 0.29 \mu \mathrm{g} / \mathrm{mL}\right)>4-(3,4-$ dihydroxyphenyl)but-3-en-2-one (3) (IC50: 80.32 $\pm 0.98 \mu \mathrm{g} / \mathrm{mL}$ ) > pinoresinol (2) (IC50: $85.69 \pm 0.87 \mu \mathrm{g} / \mathrm{mL})>$ ergosta-7,24(28)-dien-3 $\beta$-ol (1) (IC50: $95.05 \pm 1.25 \mu \mathrm{g} / \mathrm{mL})$. Toxicity on CCD-18Co was decreased in the order of $P$. pini methanol extract (IC $50: 434.30 \pm 1.45 \mu \mathrm{g} / \mathrm{mL}$ ) $>$ 
ergosta-7,24(28)-dien-3 $\beta$-ol (1) (IC50:347.20 $\pm 0.78 \mu \mathrm{g} / \mathrm{mL})>$ pinoresinol (2) (IC $50: 293.90 \pm 0.46$ $\mu \mathrm{g} / \mathrm{mL})>4$-(3,4-dihydroxyphenyl)but-3-en-2-one (3) (IC50: 245.20 $\pm 0.34 \mu \mathrm{g} / \mathrm{mL}$ ) (Table 1).

From ancient times, people have described mushrooms as culinary wonders and valuable in folk medicine. In recent years, mushrooms have witnessed the intense interest of scientists due to their pharmaceutical potentials (Dimitrijevic et al., 2017). Until this time, the medicinal uses of mushrooms have been associated with their nephroprotective, antioxidant, antitumor, hypocholesterolemic, antidiabetic, immunomodulatory, anti-cancer, antiallergic, and antimicrobial properties. Literature studies have shown that Phellinus, Agaricus, Pleurotus, Clitocybe, Ganoderma, Antrodia, Cordyceps, Trametes, Calvatia, Xerocomus, Flammulina, Schizophyllum, Suillus, Inonotus, Funlia, Inocybe, Lactarius, Russula, Albatrellus, and Fomes mushroom species are effective against cancer. These mushroom species are defined as new generation biotherapeutics (Patel \& Goyal, 2012). It is prominent that not only active isolated compounds but also extracts containing active compounds can be used as alternative agents with fewer side effects in cancer treatment and hence it is important to examine the cytotoxic effects of the mushroom species. According to the results obtained, it was determined that $P$. pini methanol extract has the best cytotoxic activity. In earlier studies, purification and bioactive properties of steroids, phenolics, terpenoids, and polysaccharides from $P$. pini have been reported (Deveci et al., 2019ª; Deveci et al., 2019 ; Hong et al., 2013; Jang \&Yang, 2011). Therefore, the higher cytotoxic activity of the methanol extract compared to other isolated compounds can be explained by the synergistic effect of various bioactive compounds contained in it. Among the isolated compounds, phenolic compounds indicated higher cytotoxic properties. It is known that phenolic compounds have anticancer activity associated with their high antioxidant properties or have direct cytotoxic effects on cancer cells (Ivanova et al., 2014). Also, the cytotoxic mechanism of action of phenolic compounds has been elucidated in previous studies as modulating carcinogen metabolism, altering gene expression levels, arresting the cell cycle, inducing apoptosis, and inhibiting various cell proliferation signaling pathways (Huang et al., 2010).

Previously, cytotoxic effects of the extracts, fractions, and pure compounds obtained from different Phellinus species on colorectal cancer were determined with a limited number of studies. In the study of Reis et al. (2014), the methanol (GI50:70 $\pm 3 \mu \mathrm{g} / \mathrm{mL}$ ) and ethanol (GI50: $61 \pm 1 \mu \mathrm{g} / \mathrm{mL}$ ) extracts as also polysaccharides (GI50: $87 \pm 4 \mu \mathrm{g} / \mathrm{mL})$, glucans $\left(\mathrm{GI}_{50}: 202 \pm 4\right.$ $\mu \mathrm{g} / \mathrm{mL}$ ), and triterpenoids (GI50: $65 \pm 1 \mu \mathrm{g} / \mathrm{mL}$ ) fractions of $P$. linteus were tested for cytotoxic effects on HCT-15 (colorectal cancer). The hispidine isolated from $P$. linteus has been reported to be a promising new anticancer agent due to inducing both intrinsic and extrinsic apoptotic pathways mediated by ROS in CMT-93 (mouse colorectal cancer) and HCT-116 (human colorectal cancer) cells (Lim, Lee, Park, Kim, \& Lim, 2014). He et al. (2015) purified two illudin type sesquiterpenoids, sulphureuine A and phellinuin $\mathrm{J}$ from $P$. tuberculosus, tested these compounds for their inhibitory effects on SW480 (colorectal cancer) and no significant inhibitory activity was reported ( $\mathrm{IC}_{50}:>40 \mathrm{mM}$ ). Inhibition rates of 24-ethylcholesta-5,22-dien$3 \beta$-ol, ergosterol, 3,4-dihydroxy benzaldehyde, ergosta-7,22-dien-3 $\beta$-yl pentadecanoate, baicalein and inoscavin A purified from $P$. baumii on SW620 (colorectal cancer) were reported as $\sim 40, \sim 30, \sim 50, \sim 40, \sim 90$ and $\sim 90 \%$, respectively at $100 \mu \mathrm{g} / \mathrm{mL}$ concentration. Also, inoscavin A and baicalein were found to have higher cytotoxic activity than 5-fluorouracil that served as a positive control (Zhang et al., 2017). Ethyl acetate extract (IC50: $149.9 \mu \mathrm{g} / \mathrm{mL}$ ), $n$-hexane (IC50: $69.8 \mu \mathrm{g} / \mathrm{mL}$ ), $n$-butanol (IC50: $>100 \mu \mathrm{g} / \mathrm{mL}$ ) and ethyl acetate (IC50: $77.8 \mu \mathrm{g} / \mathrm{mL}$ ) fractions and atractylenolide I ( $20 \%$ cell viability at $100 \mu \mathrm{g} / \mathrm{mL}$ concentration) from $P$. linteus were investigated for their cytotoxic effects on HT-29 (colorectal cancer) by Jeon et al. (2013). There are studies on the cytotoxic effects of different mushroom species on DLD-1 (colorectal cancer) in the literature. $\mathrm{IC}_{50}$ values of the $n$-hexane, chloroform, and ethyl acetate subfractions of Tremella fuciformis were found as 350, 400, and $450 \mathrm{ppm}$, respectively against DLD-1 
(colorectal cancer) (Kim, Chang, Choi, Yoon, \& Lee, 2006). In a different study, at 0.2 and 0.5 $\mathrm{mg} / \mathrm{mL}$ concentrations, Inonotus obliquus water extract inhibited $48 \%$ and $62 \%$ proliferation of HCT-116 and $40 \%$ and $60 \%$ proliferation of DLD-1 colorectal cancer cells and it was reported that the water extract downregulated the $\beta$-catenin and NF-kB signaling, which exerted antiinflammatory and antiproliferative activities in colorectal cancer cells (Mishra et al., 2013). Ergosterol peroxide isolated from Inonotus obliquus was screened for cytotoxic activity against HCT-116, HT-29, SW620, and DLD-1 colorectal cancer cells at 0, 5, 10, $20 \mu \mathrm{g} / \mathrm{mL}$ concentrations. When the cell growth of HCT-116, HT-29, SW620 were found nearly 20\% at $20 \mu \mathrm{g} / \mathrm{mL}$ concentration, the cell growth of DLD-1 was found nearly $\sim 80 \%$ at $20 \mu \mathrm{g} / \mathrm{mL}$ concentration (Kang et al., 2015). Our results are in agreement with the literature studies. This is the first investigation on cytotoxic activities of $P$. pini methanol extract and isolated compounds against DLD-1 and CCD-18Co cells.

\section{CONCLUSION}

Chemotherapy, cytotoxic drugs, radiotherapy, and surgery are the main methods used in the treatment of colorectal cancer. Among these methods, the most effective method is surgery, and treatment is continued with chemotherapy or radiotherapy since there is a high possibility of recurrence of colorectal cancer after surgery. The negative side effects of chemotherapy compounded by the tendency of colorectal cancer reoccurrence, has made it imperative to search for new, natural, and effective agents with fewer side effects in its treatment. Cytotoxicity of $P$. pini methanol extract and ergosta-7,24(28)-dien-3 $\beta$-ol (1), pinoresinol (2), and 4-(3,4-dihydroxyphenyl)but-3-en-2-one (3) isolated compounds were investigated on DLD-1 and CCD-18Co cells for the first time. The methanol extract of $P$. pini displayed significant cytotoxicity on DLD-1. As a result, this study recommends that $P$. pini mushroom, especially the methanol extract, can be used for further research that could lead to the development of new natural remedies in the treatment of colorectal cancer.

\section{Declaration of Conflicting Interests and Ethics}

The authors declare no conflict of interest. This research study complies with research publishing ethics. The scientific and legal responsibility for manuscripts published in IJSM belongs to the author(s).

\section{Authorship contribution statement}

Ebru Deveci: Investigation, Visualization, Software, Formal Analysis, Methodology, Writingoriginal draft, Supervision. Gulsen Tel-Cayan: Investigation, Visualization, Software, Formal Analysis, Methodology, Writing-original draft, Supervision. Serdar Karakurt: Resources, Methodology, Validation. Mehmet Emin Duru: Resources, Methodology, Formal Analysis, Validation.

\section{Orcid}

Ebru Deveci (D) https://orcid.org/0000-0002-2597-9898

Gulsen Tel-Cayan (D) https://orcid.org/0000-0002-1916-7391

Serdar Karakurt $\mathbb{D}$ https://orcid.org/0000-0002-4449-6103

Mehmet Emin Duru (D) https://orcid.org/0000-0001-7252-4880

\section{REFERENCES}

Arnold, M., Sierra, M.S., Laversanne, M., Soerjomataram, I., Jemal, A., \& Bray, F. (2017). Global Patterns and Trends in Colorectal Cancer Incidence and Mortality. Gut, 66, 683691. http://dx.doi.org/10.1136/gutjnl-2015-310912 
Ayer, W.A., Muir, D.J., \& Chakravarty, P. (1996). Phenolic and Other Metabolites of Phellinus pini, A Fungus Pathogenic to Pine. Phytochemistry, 42, 1321-1324. http://doi.org/10.10 16/0031-9422(96)00125-2

Dekker, E., Tanis, P.J., Vleugels, J.L.A., Kasi, P.M., \& Wallace, M.B. (2019). Colorectal Cancer. Lancet, 394, 1467-1480. https://doi.org/10.1016/S0140-6736(19)32319-0

Deveci, E., Tel-Çayan, G., Duru, M.E., \& Öztürk, M. (2019ª). Chemical Constituents of Porodaedalea pini Mushroom with Cytotoxic, Antioxidant and Anticholinesterase Activities. J. Food Meas. Charact., 13, 2686-2695. https://doi.org/10.1007/s11694-01900189-2

Deveci, E., Çayan, F., Tel-Çayan, G., \& Duru, M.E. (2019 $)$. Structural Characterization and Determination of Biological Activities for Different Polysaccharides Extracted from Tree Mushroom Species. J. Food Biochem., 43(9), e12965. https://doi.org/10.1111/jfbc.12965

Dimitrijevic, M., Jovanovic, V.S., Cvetkovic, J., Mitic, M., Petrovic, G., Dordevic, A., \& Mitic, V. (2017). Phenolics, Antioxidant Potentials, and Antimicrobial Activities of Six Wild Boletaceae Mushrooms. Anal. Lett., 50, 1691-1709. https://doi.org/10.1080/00032719.2 016.1242133

Ganeshpurkar, A., Rai, G., \& Jain, A.P. (2010). Medicinal Mushrooms: Towards A New Horizon. Pharmacogn. Rev., 4(8), 127-135. https://doi.org/10.4103/0973-7847.70904

He, J.B., Tao, J., Miao, X.S., Feng, Y.P., Bu, W., Dong, Z.J., Li, Z.H., Feng, T., \& Liu, J.K. (2015). Two New Illudin Type Sesquiterpenoids from Cultures of Phellinus tuberculosus and Laetiporus sulphureus. J. Asian Nat. Prod. Res., 17, 1054-1058. https://doi.org/10.1080/10286020.2015.1040774

Hong, Y.J., Jang, A.R., \& Yang, K.S. (2013). Inhibition of Melanin Production and Tyrosinase Expression of Ergosterol Derivatives from Phellinus pini. Nat. Prod. Sci., 19(3), 258-262.

Huang, W.Y., Cai, Y.Z. \& Zhang, Y. (2010). Natural Phenolic Compounds from Medicinal Herbs and Dietary Plants: Potential Use for Cancer Prevention. Nutr. Cancer, 62(1), 120. https://doi.org/10.1080/01635580903191585

Ivanova, T.S., Krupodorova, T.A., Barshteyn, V.Y., Artamonova, A.B., \& Shlyakhovenko, V.A. (2014). Anticancer Substances of Mushroom Origin. Exp. Oncol., 36(2), 58-66.

Jang, H.J., \& Yang, K.S. (2011). Inhibition of Nitric Oxide Production in RAW 264.7 Macrophages by Diterpenoids from Phellinus pini. Arch. Pharm. Res., 34, 913-917. https://doi.org/10.1007/s12272-011-0608-z

Jeon, T.I., Jung, C.H., Cho, J.Y., Park, D.K., \& Moon, J.H. (2013). Identification of an Anticancer Compound Against HT-29 Cells from Phellinus linteus Grown on Germinated Brown Rice. Asian Pac. J. Trop. Biomed., 3(10), 785-789. https://doi.org/10.1016/S22211691(13)60156-2

Kang, J.H., Jang, J.E., Mishra, S.K., Lee, H.J., Nho, C.W., Shin, D., Jin, M., Kim, M.K., Choi, C., \& Oh, S.H. (2015). Ergosterol Peroxide from Chaga Mushroom (Inonotus obliquus) Exhibits Anti-Cancer Activity by Down-Regulation of the $\beta$-Catenin Pathway in Colorectal Cancer. J. Ethnopharmacol., 173, 303-312. https://doi.org/10.1016/j.jep.2015 .07 .030

Karakurt, S., \& Adali, O. (2016). Tannic Acid Inhibits Proliferation, Migration, Invasion of Prostate Cancer and Modulates Drug Metabolizing and Antioxidant Enzymes. AntiCancer Agents Med Chem., 16(6), 781-789. https://doi.org/10.2174/1871520616666151 111115809

Kelly, J.J., Alberts, S.R., Sacco, F., \& Lanier, A.P. (2012). Colorectal Cancer in Alaska Native People, 2005-2009. Gastrointes. Cancer Res., 5, 149-154.

Kim, K.A., Chang, H.Y., Choi, S.W., Yoon, J.W., \& Lee, C. (2006). Cytotoxic Effects of Extracts from Tremella fuciformis Strain FB001 on the Human Colon Adenocarcinoma Cell Line DLD-1. Food Sci. Biotechnol., 15(6), 889-895. 
Lim, J.H., Lee, Y.M., Park, S.R., Kim, D.H., \& Lim, B.O. (2014). Anticancer Activity of Hispidin via Reactive Oxygen Species-Mediated Apoptosis in Colon Cancer Cells. Anticancer Res., 34, 4087-4094.

Mishra, S.K., Kang, K.H., Song, K.H., Park, M.S., Kim, D.K., Park, Y.J., Chop, C., Kim, H.M., Kim, M.K., \& Oh, S.H. (2013). Inonotus obliquus Suppresses Proliferation of Colorectal Cancer Cells and Tumor Growth in Mice Models by Downregulation of $\beta$-Catenin/NFkB-Signaling Pathways. Eur. J. Inflamm., 11, 615-629. https://doi.org/10.1177/1721727 X1301100306

Oba, S., Shimizu, N., Nagata, C., Shimizu, H., Kametani, M., Takeyama, N., Ohnuma, T., \& Matsushita, S. (2006). The Relationship Between the Consumption of Meat, Fat, and Coffee and the Risk of Colon Cancer: A Prospective Study in Japan. Cancer Lett., 244, 260-267. https://doi.org/10.1016/j.canlet.2005.12.037

Patel, S., \& Goyal, A. (2012). Recent Developments in Mushrooms as Anti-Cancer Therapeutics: A Review. 3 Biotech., 2, 1-15. https://doi.org/10.1007/s13205-011-0036-2

Pei, J.J., Wang, Z.B., Ma, H.L., \& Yan, J.K. (2015). Structural Features and Antitumor Activity of A Novel Polysaccharide from Alkaline Extract of Phellinus linteus Mycelia. Carbohyd. Polym., 115, 472-477. https://doi.org/10.1016/j.carbpol.2014.09.017

Perdue, D.G., Haverkamp, D., Perkins, C., Daley, C.M., \& Provost, E. (2014). Geographic Variation in Colorectal Cancer Incidence and Mortality, Age of Onset, and Stage at Diagnosis Among American Indian and Alaska Native People, 1990-2009. Am. J. Public Health, 104, 404-414. https://doi.org/10.2105/AJPH.2013.301654

Reis, F.S., Barreira, J.C.M., Calhelha, R.C., van Griensven, L.J.I.D., Ciric, A., Glamoclija, J., Soković, M., \& Ferreira, I.C.F.R. (2014). Chemical Characterization of the Medicinal Mushroom Phellinus linteus (Berkeley \& Curtis) Teng and Contribution of Different Fractions to Its Bioactivity. LWT-Food Sci. Technol., 58, 478-485. https://doi.org/10.1016/j.lwt.2014.04.013

Seephonkai, P., Samchai, S., Thongsom, A., Sunaart, S., Kiemsanmuang, B., \& Chakuton, B. (2011). DPPH Radical Scavenging Activity and Total Phenolics of Phellinus Mushroom Extracts Collected from Northeast of Thailand. Chinese J. Nat. Med., 9(6), 0441-0445. https://doi.org/10.3724/SP.J.1009.2011.00441

Seidel, D.V., Azcarate-Peril, M.A., Chapkin, R.S., \& Turner, N.D. (2017). Shaping Functional Gut Microbiota Using Dietary Bioactives to Reduce Colon Cancer Risk. Sem. Cancer Biol., 46, 191-204. https://doi.org/10.1016/j.semcancer.2017.06.009

Song, A.R., Sun, X.L., Kong, C., Zhao, C., Qin, D., Huang, F., \& Yang, S. (2014). Discovery of A New Sesquiterpenoid from Phellinus ignarius with Antiviral Activity Against Influenza Virus. Arch. Virol., 159, 753-760. https://doi.org/10.1007/s00705-013-1857-6

Surya, R., Héliès-Toussaint, C., Martin, O.C., Gauthier, T., Guéraud, F., Taché, S., Naud, N., Jouanin, I., Chantelauze, C., Durand, D., Joly, C., Pujos-Guillot, E., Pierre, F.H., \& Huc, L. (2016). Red Meat and Colorectal Cancer: Nrf2-Dependent Antioxidant Response Contributes to the Resistance of Preneoplastic Colon Cells to Fecal Water of Hemoglobinand Beef-Fed Rats. Carcinogenesis, 37, 635-645. https://doi.org/10.1093/ca $\mathrm{rcin} / \mathrm{bgw} 035$

Takachi, R., Tsubono, Y., Baba, K., Inoue, M., Sasazuki, S., Iwasaki, M., \& Tsugane, S. (2011). Red Meat Intake May Increase the Risk of Colon Cancer in Japanese, A Population with Relatively Low Red Meat Consumption. Asia Pac. J. Clin. Nutr., 20, 603-612.

Tao, J., Li, Y., Li, S., \& Li, H.B. (2018). Plant Foods for the Prevention and Management of Colon Cancer. J. Funct. Foods, 42, 95-110. https://doi.org/10.1016/j.jff.2017.12.064

Turati, F., Rossi, M., Pelucchi, C., Levi, F., \& La Vecchia, C. (2015). Fruit and Vegetables and Cancer Risk: A Review of Southern European Studies. Br. J. Nutr., 113, 102-110. https://doi.org/10.1017/S0007114515000148 
Wang, J., Hu, F., Luo, Y., Luo, H., Huang, N., Cheng, F., Deng, Z., Deng, W., \& Zou, K. (2014). Estrogenic and Anti-Estrogenic Activities of Hispolon from Phellinus lonicerinus (Bond.) Bond. et sing. Fitoterapia, 95, 93-101. https://doi.org/10.1016/j.fitote.2014.03.0 07

Wangun, H.V.K., \& Hertweck, C. (2007). Squarrosidine and Pinillidine: 3,3'-Fused Bis (Styrylpyrones) from Pholiota squarrosa and Phellinus pini. Eur. J. Org. Chem., 2007, 3292-3295. https://doi.org/10.1002/ejoc.200700090

Wu, X., Lin, S., Zhu, C., Yue, Z., Yu, Y., Zhao, F., Liu, B., Dai, J., \& Shi, J. (2010). Homoand Heptanor-Sterols and Tremulane Sesquiterpenes from Cultures of Phellinus igniarius. J. Nat. Prod., 73(7), 1294-1300. https://doi.org/10.1021/np100216k

Zhang, H., Shao, Q., Wang, W., Zhang, J., Zhang, Z., Liu, Y., \& Yang, Y. (2017). Characterization of Compounds with Tumor-Cell Proliferation Inhibition Activity from Mushroom (Phellinus baumii) Mycelia Produced by Solid-State Fermentation. Molecules, 22(5), 698. https://doi.org/10.3390/molecules22050698 